\title{
Technology Development in Electric Power Generation for a Low Carbon Society*
}

\author{
Shigeru AZUHATA** \\ ${ }^{* *}$ Research and Development Group \\ Hitachi, Ltd. \\ 1-6-1 Marunouchi, Chiyoda-ku, Tokyo, JAPAN \\ E-mail: shigeru.azuhata.tf@hitachi.com
}

\begin{abstract}
Environmental issues are becoming increasingly apparent on a global scale with rising $\mathrm{CO}_{2}$ levels generated by a rapidly growing human population. At the same time, as pointed out by the Club of Rome in 1972, this population growth is also accelerating consumption of natural resources. In relation to $\mathrm{CO}_{2}$ reduction, a two-prong approach is being taken to reduce $\mathrm{CO}_{2}$ from the energy generation side and also from consumption side. On the generation side, we are concentrating on the proliferation of low-carbon energy such as nuclear and renewable energies, as well as increasing plant efficiency in thermal power generation along with Carbon-Capture-and-Storage (CCS) technologies. On the consumption side, efficient energy storage devices such as batteries are becoming a key issue in effective energy utilization together with the ongoing challenge towards ever greater efficiency of motors and inverters. This paper discusses current research activities in power generation technologies.
\end{abstract}

Key words: Nuclear Power Generation, Renewable Energy, Solar Power, Wind Power, Carbon-Capture-and-Storage, Smart Grid

\section{Introduction}

IPCC "Climate Change 2007: Mitigation of Climate Change" gives increasing evidence supporting anthropogenic causes in global climate change, in particular rising levels of Green House Gas (GHG) concentrations as one of the main causes of rise in average global temperature. In order to stabilize GHG concentrations between 445 and $710 \mathrm{ppm}$ by 2030, the global GDP loss is predicted to be between less than $3 \%$ to a gain of $0.6 \%$, which is an annual reduction in GDP growth of $0.12 \%$ to $0.06 \%$. $^{(1)(2)}$ However, as Sir Nicholas Stern states in "The Economics of Climate Change," "The evidence shows that ignoring climate change will eventually damage economic growth. Our actions over the coming few decades could create risks of major disruption to economic and social activity, later in this century and in the next, on a scale similar to those associated with the great wars and the economic depression of the first half of the 20th century. And it will be difficult or impossible to reverse these changes. Tackling climate change is the pro-growth strategy for the longer term, and it can be done in a way that does not cap the aspirations for growth of rich or poor countries. The earlier effective action is taken, the less costly it will be." (3)

At COP3 held in Kyoto in 1997, a goal to reduce GHG emissions over five years

*Received 29 Oct., 2010 (No. 10-231-9) [DOI: 10.1299/jpes.5.195]

Copyright $@ 2011$ by JSME 
between 2008 to 2012 was decided, and the G8 leaders reached a consensus of $50 \%$ reduction in global $\mathrm{CO}_{2}$ emissions by 2050 at the G8 Summit held in Heiligendamm, Germany. The IEA formulated a future energy policy scenario in response to the G8 Summit and released many reports, in particular, Energy Technology Perspective 2008 which proposed a blueprint to achieve $50 \% \mathrm{CO}_{2}$ emissions reductions by 2050 with breakthrough technologies to mitigate $\mathrm{CO}_{2}$ emissions like renewables, saving energy, and Carbon Capture and Storage (CCS) ${ }^{(4)}$ From Japan, the former prime minister Mr. Yasuo Fukuda had announced Cool Earth Credit of 10 Billion USD for developing countries and development investment of 30 billion USD for R\&D in energy technologies at the World Economic Forum in Davos (Davos Forum) in 2008, followed by an announcement from the Ministry of Economy, Trade and Industry of the "Cool Earth - Innovative Energy Technology Program.”

There are several approaches and options to meeting the challenges being raised. In order to decrease GHG emission produced by the combustion of fossil fuels, our current options are nuclear energy and renewable energy. Addressing the $3 \mathrm{~S}$ issues of security, safety and safeguards are extremely important in former, and in the latter, there is the challenge of providing a stable and reliable supply ${ }^{(5)(6)}$. Both are costly in comparison to current thermal power generation either in terms of facility investment or because the technology is still at a young stage, lack the supporting infrastructure and immediate results of high productivity and reliability cannot be expected. An interim or harmonizing option being pursued is the increased efficiency of thermal power generation and the removal of GHG gases through CCS technology, etc. as coal and natural gas are still available in abundance and relatively cheap. The development and implementation of the Smart Grid system will be essential in order to ensure a stable supply of energy from multiple sources. This paper discusses the technology developments in the respective approaches.

\section{Solutions to the Global Environmental Issue}

Figure 1 shows the breakdown of sources for electrical power. Coal, oil and Liquid Natural Gas (LNG) consist of approximately $70 \%$ of the fuel source used in thermal power generation, and it is expected that this ratio will continue for another 10 years.

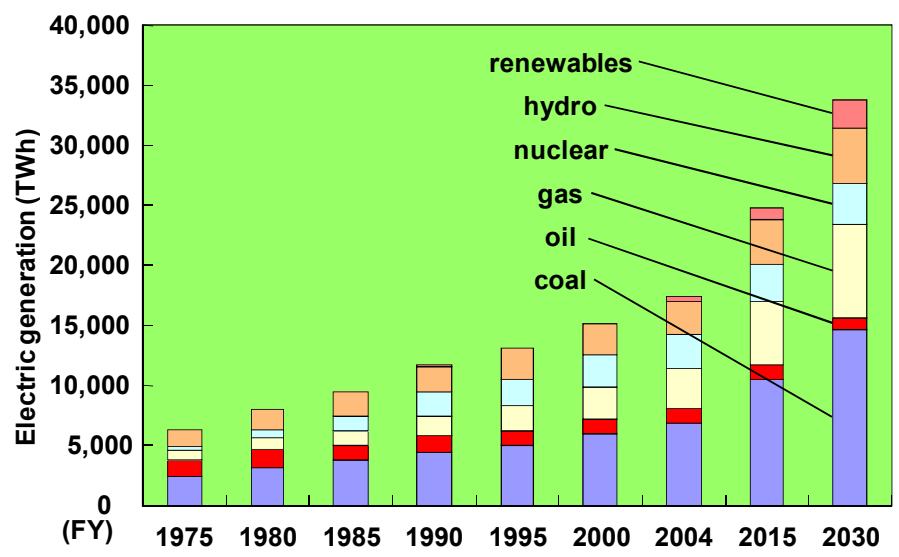

Fig. 1 Worldwide trend in electrical power source

While new energy sources such as wind power and solar power will increase, the conventional thermal, nuclear and hydraulic power will still be a fundamental source of electricity. One reason for this is that coal is still the cheapest fuel source and huge reserves still exist world-wide. Thus, electric generation using coal is expected to still 
represent a hefty $40 \%$ in 2030 , especially in developing nations. With regard to nuclear energy, safeguards, safety and security (3S) are major concerns which will need to be fully satisfied before greater proliferation can be expected. Proliferation of hydraulic plants is expected to be limited due to regional constraints based on the availability of suitable water ways and geographic structure. Renewable energy depends strongly on weather conditions and thus stable supply will continue to be an issue as well as the initial high costs involved in developing the technology and establishing the necessary infrastructure.

In terms of GHG emission, the amount of $\mathrm{CO}_{2}$ emitted per unit electricity generated is largest in coal power plants, followed by oil power plants and LNG power plants. $\mathrm{CO}_{2}$ emission from nuclear power generation is minimal, however, technical issue still need to be solved regarding the treatment of radioactive waste from spent fuel. It is expected that on a worldwide basis, global electric generation will increase by about $50 \%$ due to economic growth in Asia, Africa and Eastern Europe.

\section{Nuclear Power Generation}

Nuclear power generation does not emit $\mathrm{CO}_{2}$ and is a very effective means of providing energy without aggravating global warming. Figure 2 shows the nuclear power generation capacity in the respective nations, with USA at the top followed by France, Japan. Although China still only ranks $10^{\text {th }}$ today, China's nuclear power generation capacity is expected to grow rapidly in future.

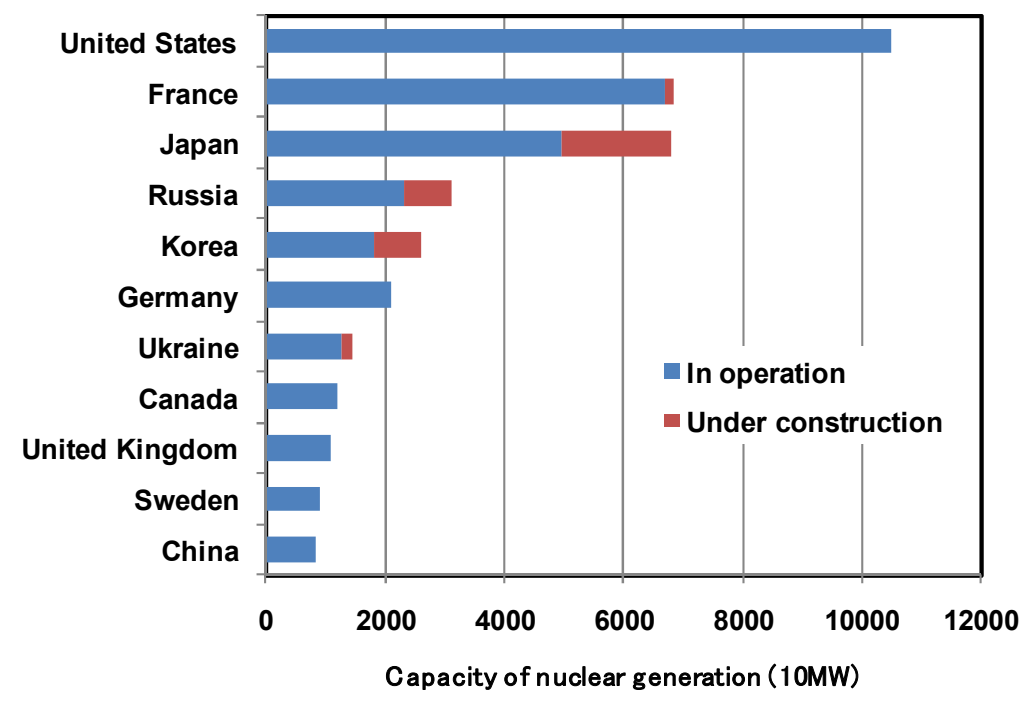

Fig 2 Nuclear power generation capacity in respective nations

Pressurize Water Reactors (PWR) represent around 70\% of current nuclear reactors in the world. In Japan, Boiling Water Reactors (BWR) are more common at 58\% with PWR representing the remaining $42 \%$. In the USA, $66 \%$ of nuclear reactors are PWR.

Figure 3 shows the technology trend in $\mathrm{BWR}^{(7)}$. Currently, Advanced BWR (ABWR) is the most common BWR type, and Economic Simplified BWR (ESBWR) and next generation BWR are being developed. As scale merit is relatively large, BWR plants have become larger and larger until now, however, as construction of larger plants have become more costly in some cases, there is also technology development undergoing for small scale ABWR to decrease initial costs. ABRW-900 as the medium-sized nuclear power plant with outstanding economical efficiency is developed based on the technology of ABWR, which is the world's first and only $3^{\text {rd }}$ generation advanced light water reactor. Since 
uranium resources are also limited, Resource-renewable Boiling Reactors (RBWR) based on the same concept as BWR but with a breeding factor of more than 1.0 is being developed.

From the viewpoint of recyclability of the fuel source, Fast Breeder Reactors (FBR) are a solution and national projects to develop this technology are currently in progress in Japan.

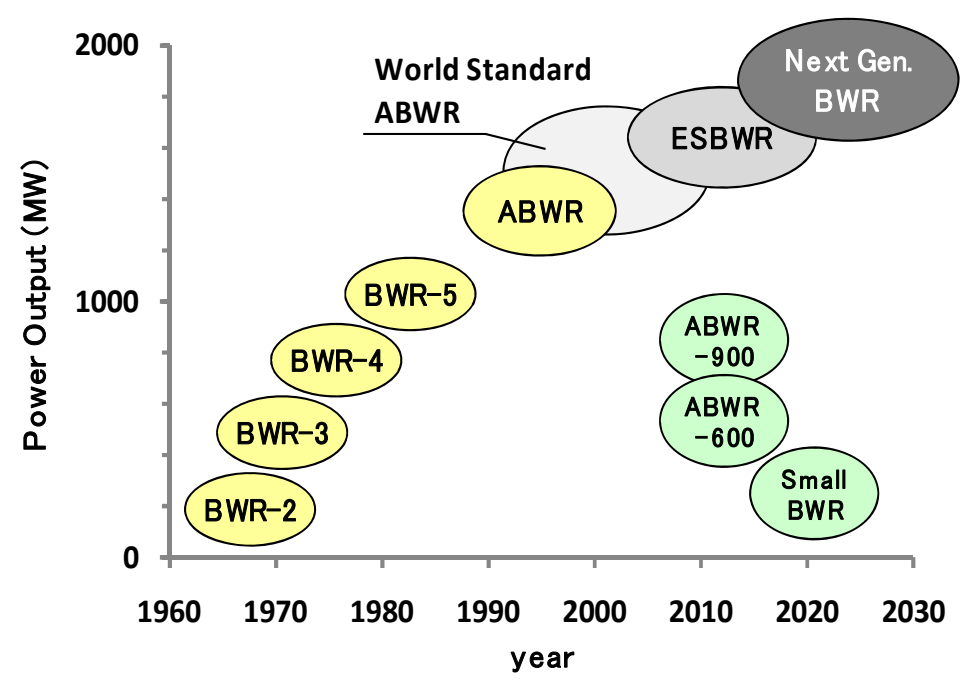

Fig. 3 Trend in BWR types

Construction and planning of new nuclear power plants are also ongoing in Japan. As part of its nuclear business, Hitachi is involved in the construction of ABWR plants as shown in Figure 4.

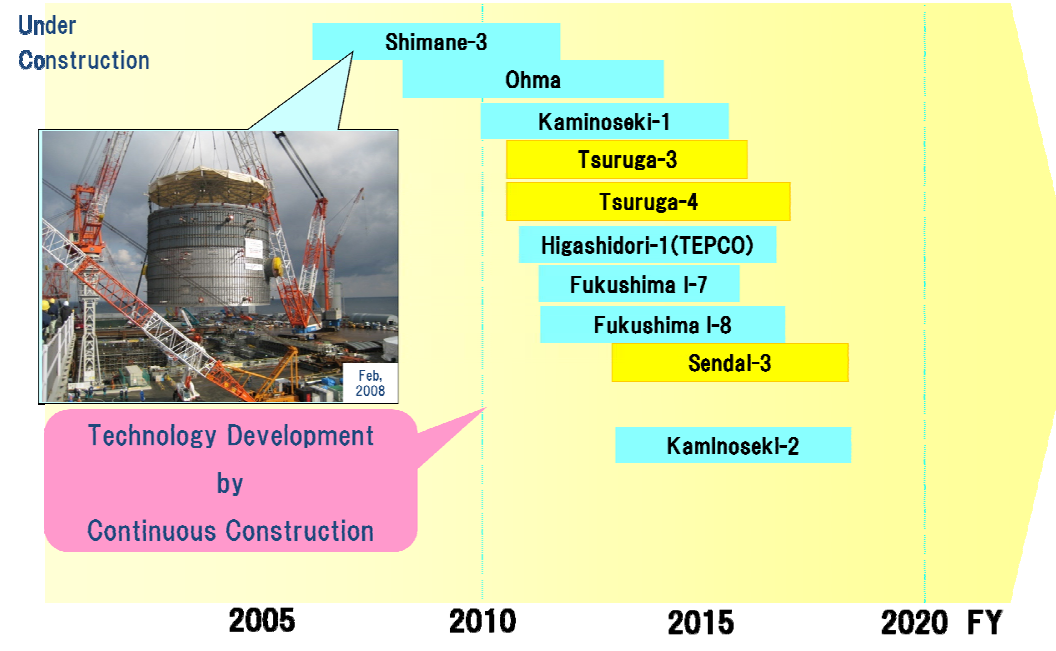

Fig. 4 Future ABWR construction plan

\section{Renewable Energy}

Figure 5 shows the expected output pattern from renewable energy sources, such as wind turbine. As the power output by renewable energy heavily depends on weather, its power output variation will substantially affect system frequency. To mitigate the power output variations, the capability to quickly absorb these load variations is required, and batteries, hydroelectric power generation and thermal power generation are adopted for this 
purpose.

To estimate the influence of a high share of renewables, the net variation is an important parameter. Figure 6 depicts the controlling method for net variation. In the case of a single wind turbine, the magnitude of variation for averaged output is rather high. On the other hand, with wide geographical dispersion of wind turbines, the magnitude of net variation can be mitigated by mutual compensation.

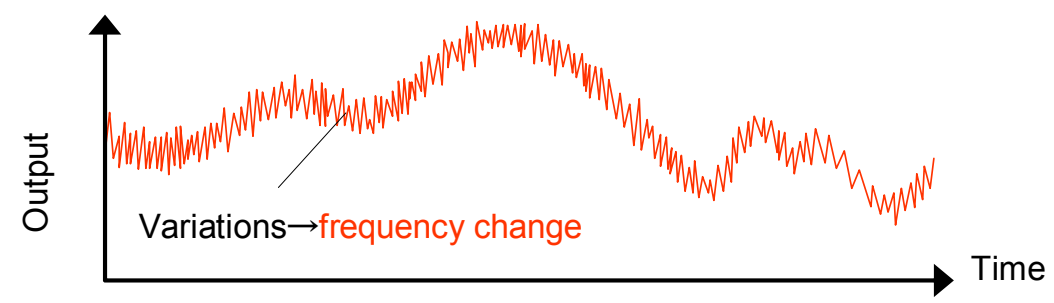

Fig. 5 Expected energy output from renewable

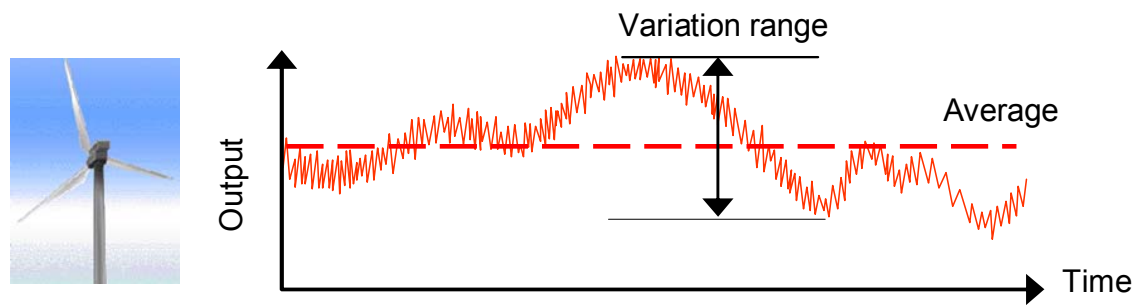

1) Output variation of a single wind turbine

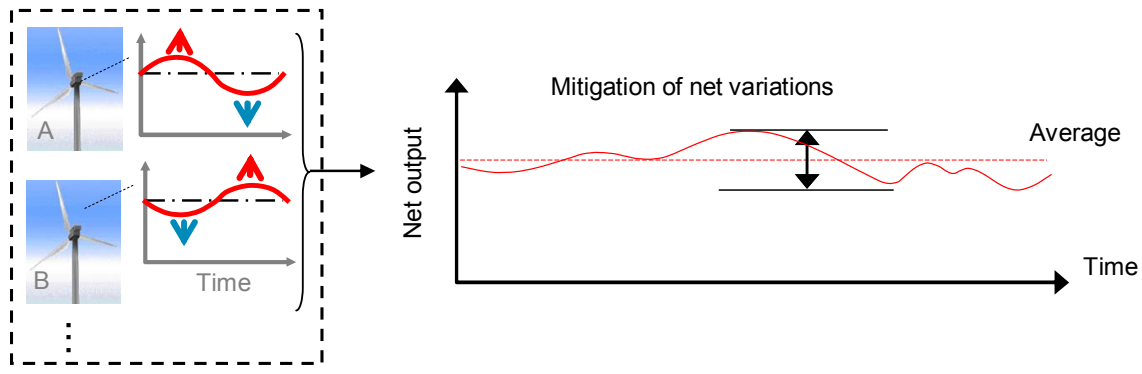

2) Net variation in geographically dispersed wind turbines

Fig. 6 Smoothing effect of variations

\subsection{Activities in Solar Power}

Figure 7 shows the Tokyo Electric Power Company, Incorporated (TEPCO) 13MW-class solar power facility which will start operation in 2011. This will be Japan's largest mega solar power system. Harmonic controlled power conditioner system (PCS) shown in Figure 8 will be incorporated in the system. Figure 8 is an example of a PCS container.

Figure 9 shows the demonstration results of the harmonic controlled PCS. The measured magnitude of harmonic consent percentage is under the limit values.

The causes of harmonics due to PCS are as follows:

1) On the PCS side: harmonics based on dead time, time discretization, etc.

2) On the power grid side: voltage harmonics, and over excitation of transformer etc.

In this system, the harmonics are mitigated by harmonic current control based on balancing between voltage harmonics from the power grid and voltage output from the PCS. 


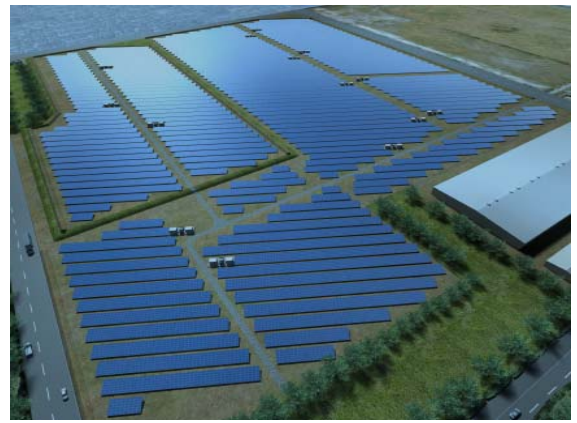

Fig. 7 13MW-class Mega Solar for TEPCO (2011: Commercial Operation)

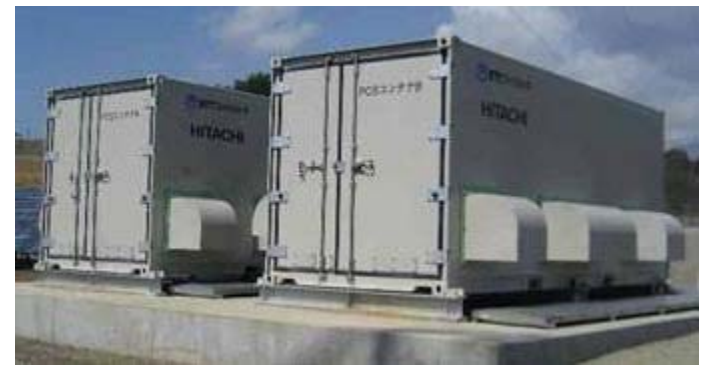

Fig.8 PCS container $(440 \mathrm{~kW})$

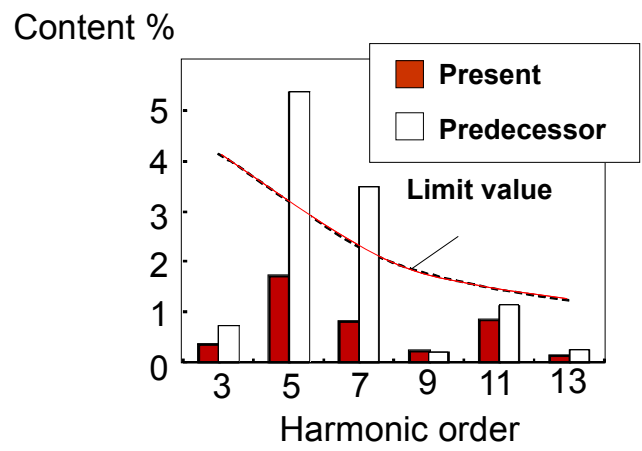

Fig. 9 Example of operation

\subsection{Activities in Wind Power}

Figure 10 shows a down-wind type wind turbine which efficiently takes advantage of the down-wind. The down-wind type can catch the normal component of the blow-up wind and the expected output increasing due to blow-up wind is approximately $7 \%$.

If renewables represent a high share of power generation sources, that is thermal power plants represent a low share, then supply adjustability will run short. In this case, instead of thermal power plants, energy storage systems will be required as shown in Figure 11. Figure 12 shows the results of smoothed output variations by charge and discharge of a battery. Figure 13 shows Japan's largest wind park with a $10 \mathrm{MWh}$ battery at Goshogawara in Aomori Prefecture, Japan. A wide installation area was required for this system. The total weight of the batteries is over $400 \mathrm{t}$. 


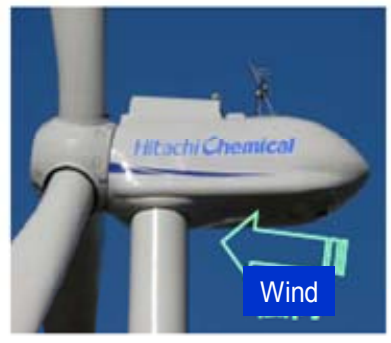

First commercial plant (2008)
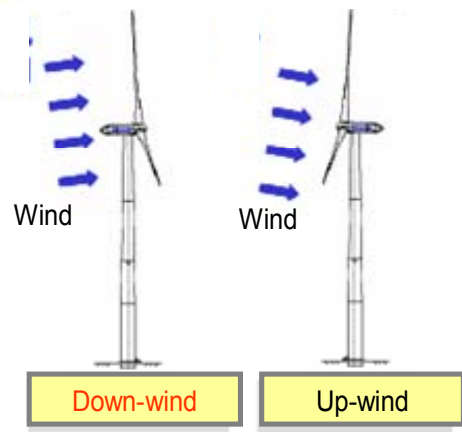

Fig. 10 Japan's largest down-wind turbine (2MW)

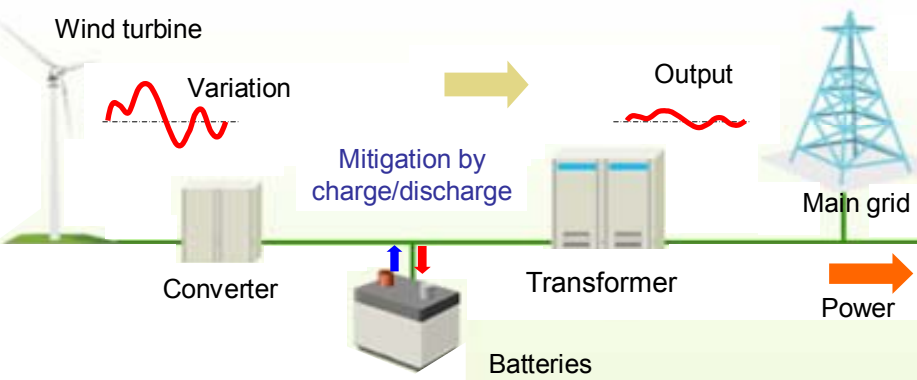

Fig. 11 Wind power system with secondary batteries

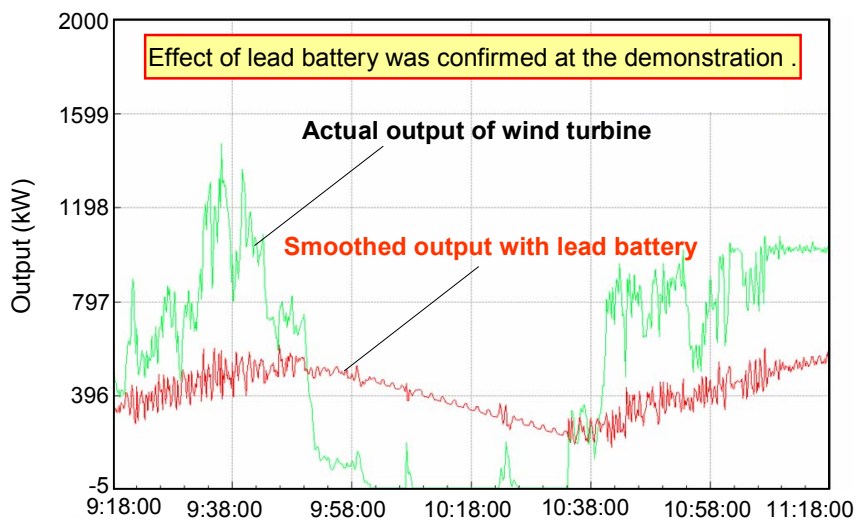

Fig. 12 Demonstration wind farm results
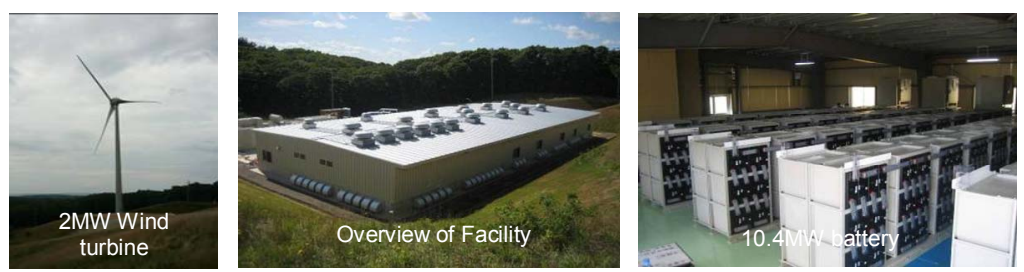

Fig.13 Demonstration wind park at Goshogawara

(Aomori, Japan)

An adjustable speed pumped hydro is an example of large-scale energy storage which will contribute to stable interconnection between main power grids and renewables. It features frequency adjustability during water pumping operation and rapid adjustability of frequency. Figure 14 illustrates how the magnitude of frequency change is improved to just under $0.14 \mathrm{~Hz}$ from more than $0.17 \mathrm{~Hz}$. 


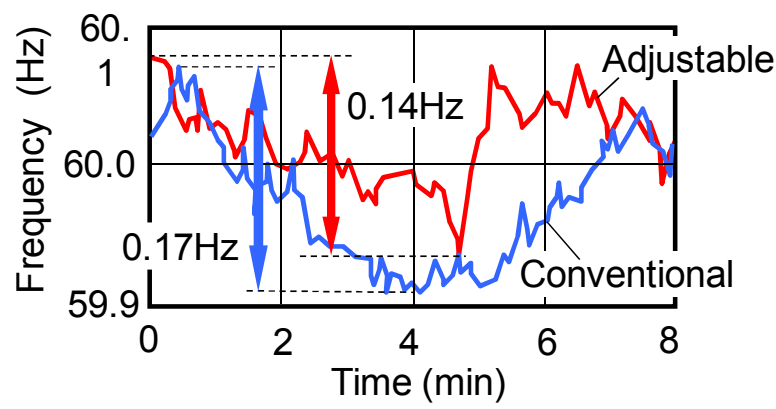

Fig. 14 Comparison of frequency adjustability

\section{Thermal Power Generation ${ }^{(8)}$}

Nuclear power, hydro-power and wind/solar power are effective in preventing global warming as they do not emit $\mathrm{CO}_{2}$ emission in the generation process but thermal power continues to provide cost-efficient base load operation as well as an effective load control function, which is critical for overall stable power generation system. In order to achieve the $50 \%$ reduction in GHG emission by 2050 as agreed at the Heiligendamm G8 summit, however, power generation efficiency must be improved, and technology to separate/capture $\mathrm{CO}_{2}$ emitted from thermal power generation needs to be actualized.

\subsection{High-Efficiency Coal Power Plant}

The price of coal is $1 / 3$ to $1 / 5$ of oil, and coal itself is abundant and ubiquitous. In fact, coal power plants represent approximately $40 \%$ of power generation plants.

As shown in Figure 15, efficiency improvements of 5\% in coal power plants were achieved between 1990 to 2010 . The improvements were mainly achieved by raising steam pressure and temperature; the current steam temperature being $600^{\circ} \mathrm{C}$ at $25 \mathrm{MPa}$ for a $600 \mathrm{MW}$ to $1000 \mathrm{MW}$ class plant. Japan has taken a leading role in developing this $600^{\circ} \mathrm{C}$-class ultra super critical pressure (USC), and the efficiency in Japanese coal power plants has been the highest since 1990. As development of robust and durable material for high temperature and pressure conditions require longer periods to confirm integrity and life-time estimation, efficiency improvement of coal power plant is slow.

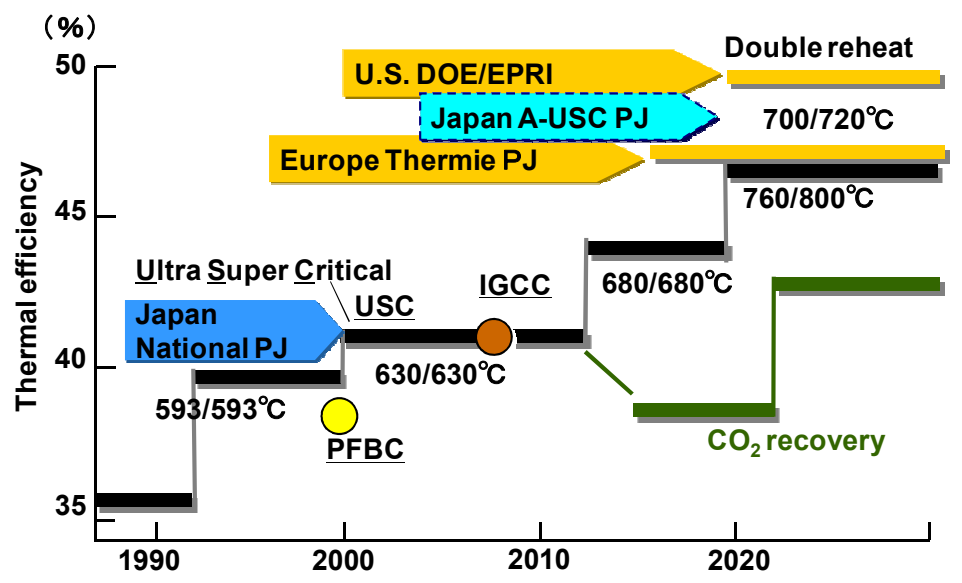

Fig. 15 Efficiency trend for Coal power plants

To further improve efficiency, a $700^{\circ} \mathrm{C}$-class advanced USC (A-USC) is under development in Europe, USA and Japan. In Europe, the THERMIE (EC Energy Directorate Research Program) project started in 1998. METI has supported this 
development in Japan. Hitachi has developed a Ni-base alloy rotor material, FENIX-700, for $700^{\circ} \mathrm{C}$-class A-USC in which there is no segregation. In addition, coal power combined cycles such as Integrated Gasification Combined Cycle (IGCC) and Pressurized Fluidized Bed Combustion (PFBC) are being commercially operated. As it will take time to achieve the necessary efficiency improvements in coal power plants, another viable short-term option in addressing GHG reduction is Carbon Capture and Storage technology.

\subsection{Carbon Capture and Storage (CCS) ${ }^{(9)-(14)}$}

To reduce $\mathrm{CO}_{2}$ emission, there are currently three major approaches: post-combustion $\mathrm{CO}_{2}$ capture, oxy-combustion, and IGCC. Since $\mathrm{CO}_{2}$ emission levels are relatively high in the $\%$ order, $\mathrm{CO}_{2}$ scrubbing however will result in substantial reduction in plant efficiency.

Amine-based $\mathrm{CO}_{2}$ separation has been utilized since the 1930s for applications such as in natural gas purification. It is a leading technology expected to be available commercially within the next decade to enable CCS for coal power stations. Traditional amine-based $\mathrm{CO}_{2}$ separation process utilizing conventional solvents, however, is very energy intensive when applied to coal power plants and also susceptible to solvent degradation by oxygen, $\mathrm{SOx}$ and $\mathrm{NO}_{2}$ in the flue gas, resulting in drastically reduced plant efficiency and output as well as large operating costs.

Figure 16 shows a sketch of a post-combustion $\mathrm{CO}_{2}$ capture process. The main system consists of an absorber and a desorber. $\mathrm{CO}_{2}$ captured from the desorber is stored in a tank after liquefication. Remaining issues in CCS are to actualize long-life amine and identify appropriate $\mathrm{CO}_{2}$ storage.

Figure 17 shows an example of a pilot plant for Post-Combustion Capture (PCC) testing in Europe. One feature of this pilot plant is its transportability which allows it to be deployed to various plant sites.

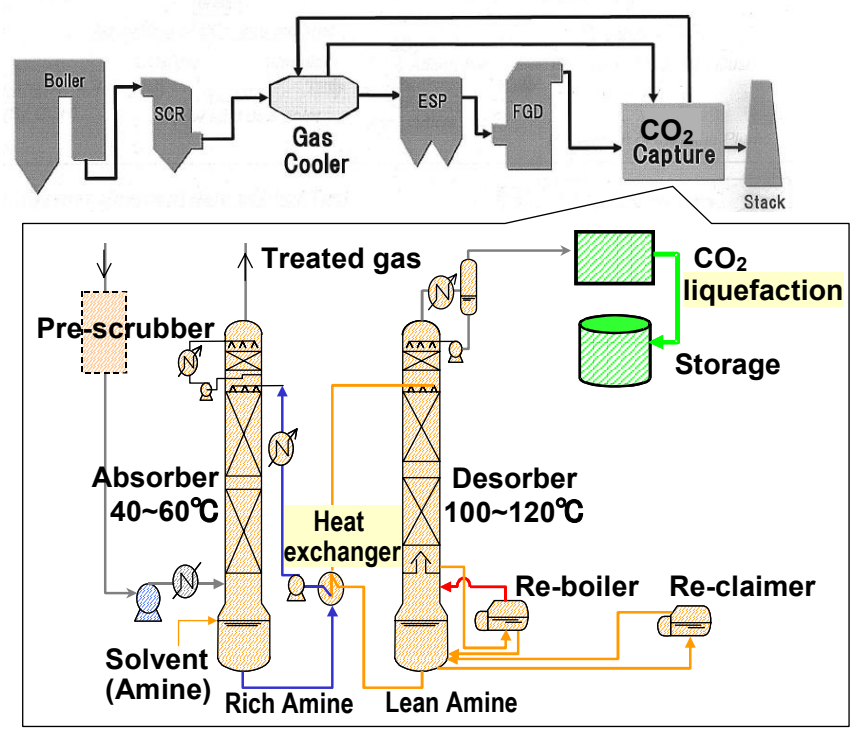

Fig. 16 Post-combustion $\mathrm{CO}_{2}$ capture process 


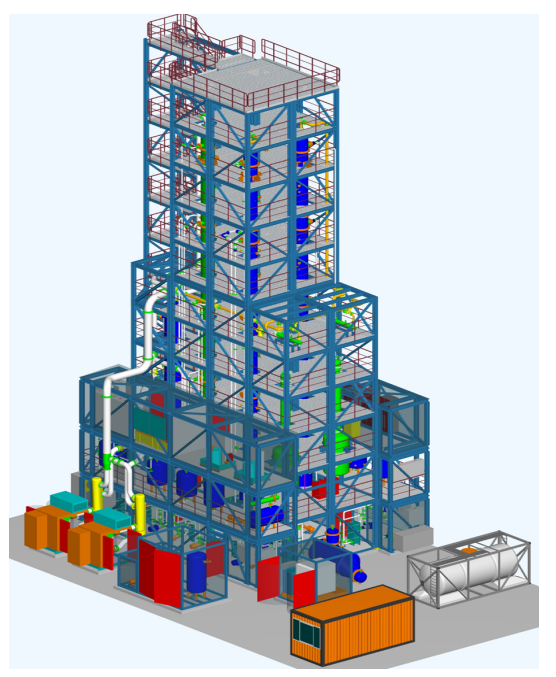

Fig. 17 Pilot plant for Post-Combustion Capture (PCC)

\subsection{High-Efficiency Gas Turbine}

Gas turbines have been used as a peak load machine due to its high load-following capability and quick start \& stop features. At present, gas turbines are often used in combined cycle plant as a base load operation facility, due to higher efficiency of combined cycle plants. As wind and solar-power facilities increase, gas turbines have been increasingly regarded as an effective frequency adjustment facility resulting in the aggressively implementation of efficiency improvements of gas turbines.

To achieve higher efficiency power generation cycles, an Advanced Humid Air Turbine (AHAT) $)^{(15)}$ based on a regenerative cycle utilizing humid air is being developed. AHAT, as shown in Figure 18, is able to achieve the equivalent efficiency to a combined cycle plant. Figure 19 shows a schematic of an AHAT system, and Figure 20 shows a 3MW-class AHAT pilot plant. The features of AHAT are a recuperator, an economizer, exhaust gas re-heater, water recovery system and Water Atomization Cooling (WAC) system. The feasibility of AHAT has been verified in a project supported by the Japanese Agency of Natural Resource and Energy, and further verification on performance, reliability, operability and economic evaluation are undergoing.

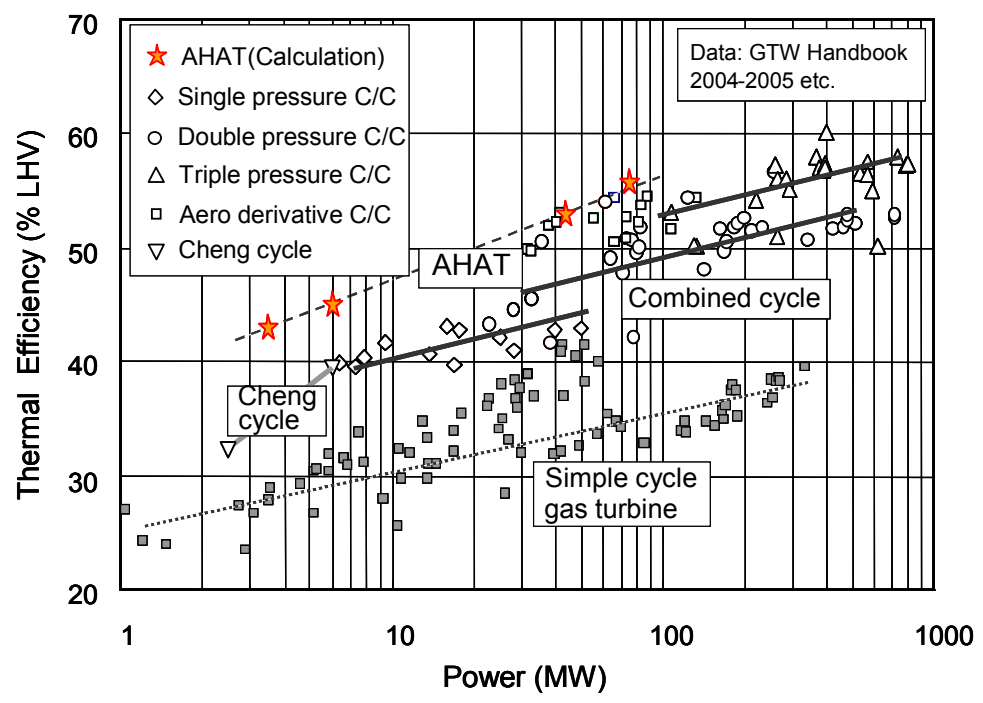

Fig. 18 Thermal efficiency of gas turbine systems 


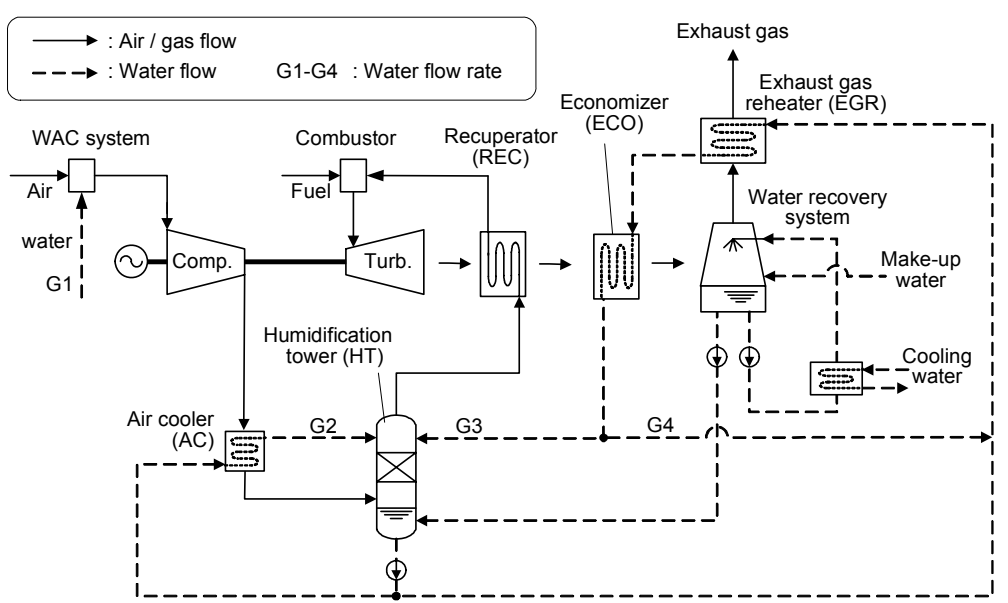

Fig. 19 Schematic of a AHAT system

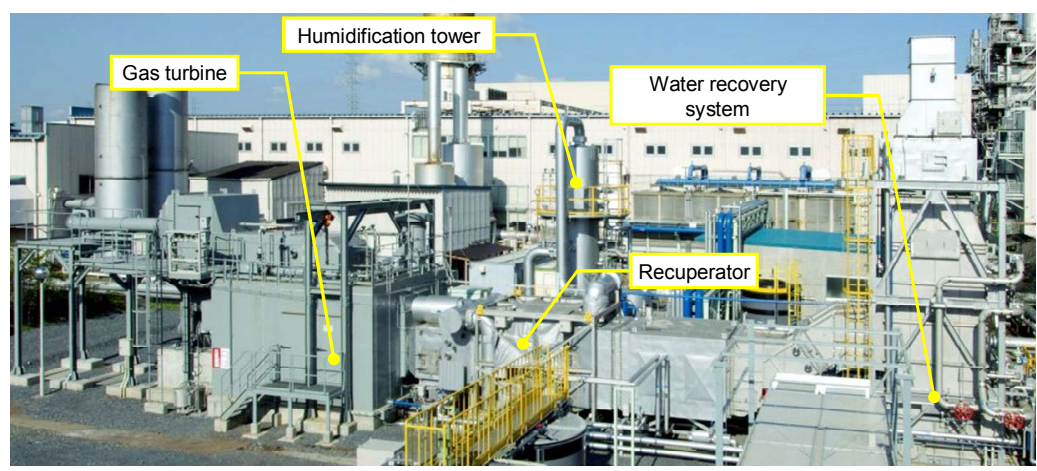

Fig. 20 3MW-class AHAT pilot plant

\section{Smart Grid ${ }^{(16)-(19)}$}

The best combination of power generators for the optimal operation of the power grid, also known as the smart grid, is being animatedly discussed. The smart grid is a generic concept related to solutions in the power grid based on information technologies, especially, interactive communication. It is therefore hard to paint a precise picture of what they are, however, according to the definition by the US Department of Energy, the smart grid includes the following 6 items:

1) Renewables' integration;

2) Demand response;

3) Electric Vehicles (EV);

4) Grid monitoring and management;

5) Integrated maintenance, and

6) Advanced metering infrastructure.

Hitachi is aggressively working on the development of smart grid technologies which is also being supported by national projects managed by NEDO. Figure 21 shows the fundamental concept of a demonstration system at Rokasho in Aomori Prefecture, Japan. In this project, the smart grid system includes renewables, EV, smart house, smart building, etc. Hitachi will be providing the Photovoltaic (PV) system with battery and grid control systems. 


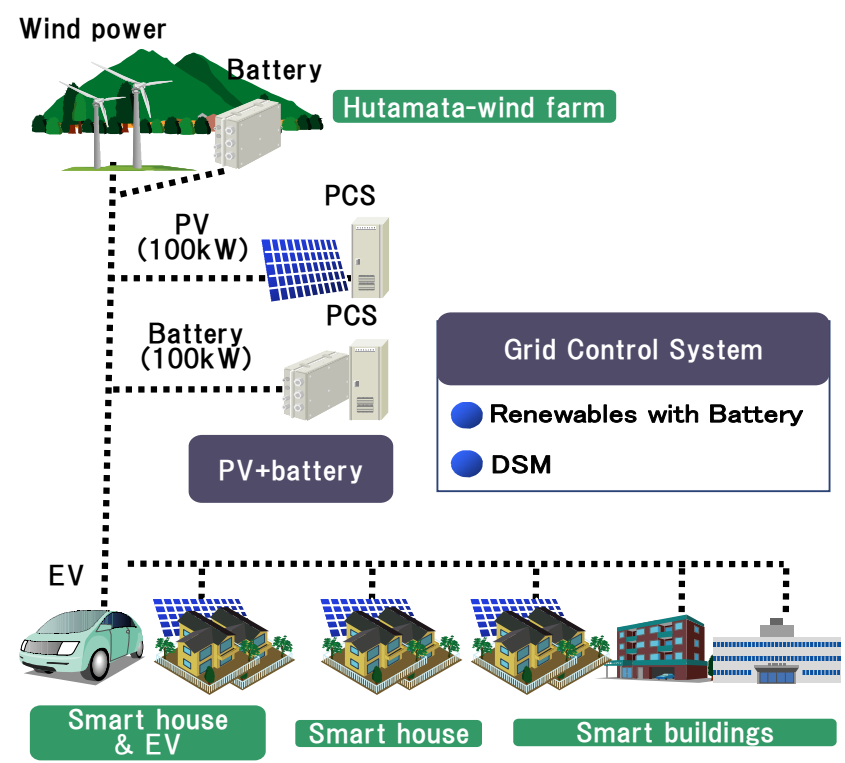

Fig. 21 Scheme of smart grid demonstration system

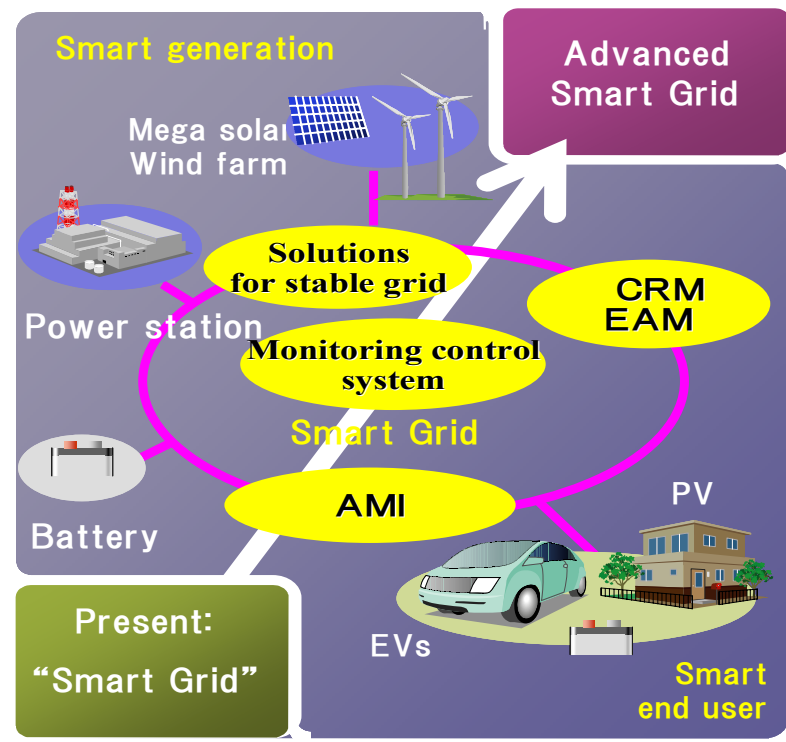

Fig. 22 Future goal of smart grid

Figure 22 shows the goal for the advanced smart grid. As mentioned above, Hitachi has many technologies to achieve a decarbonized power grid. The concept of smart end users, which includes residential PV system and plug-in electric vehicles, based on Advanced Metering Infrastructure (AMI) will contribute to energy savings and the effective usage of PV power. Further, Building Energy Management Systems (BEMS) and City Energy Management Systems (CEMS) will contribute to optimal everyday energy usage in buildings and cities. Through such integrated power grids, we hope to contribute to achieving a decarbonized society. Such a system will need to be customized for individual regions and countries

\section{Conclusion}

Several approaches are being taken to ensure various options in addressing the global energy issue with respect to demand, cost and environmental burden. As mentioned above, demand and feasible options vary regionally but fossil fuels while still abundant are not 
unlimited, and there is no doubt that future societies will need to be supported by renewable energy sources. Government policy, infrastructure and directives to facilitate this transformation will certainly assist in achieving the targets set out by IEA, but cooperation and participation on a global scale will be necessary.

Generation of GHG gases can be further alleviated by pursuing increased electric motorization and the development of efficient renewable energy storage devices. By pursuing a two-prong approach, Hitachi is working towards providing low GHG emission thermal power, safe nuclear power together with power efficient infrastructure, systems and components. Hitachi's Environmental Vision is to work towards a sustainable society through the prevention of global warming, conservation of resources and the preservation of ecosystems, and the target of its Environmental Vision 2025, a long-term plan for business activities, is to contribute to a 1000 million ton reduction in annual $\mathrm{CO}_{2}$ emission through its products and services.

\section{References}

(1) Intergovernmental Panel of Climate Change (IPPC). Climate Change 2007 - Impacts, Adaptation and Vulnerability: Working Group II contribution to the Fourth Assessment Report of the IPCC, Cambridge University Press, Cambridge, 2007.

(2) Intergovernmental Panel of Climate Change (IPPC). Climate Change 2007 Mitigation of Climate Change: Working Group III contribution to the Fourth Assessment Report of the IPCC, Cambridge University Press, Cambridge, 2007.

(3) Nicholas STERN. The Economics of Climate Change: The Stern Review. Cambridge University Press, Cambridge, 2007.

(4) International Energy Agency. Energy Technology Perspectives 2008: Scenarios and Strategies to 2050, OECD, 2008.

(5) "Response to Global Energy Issues through Strategic Alliance and the establishment of Hitachi-GE Nuclear Energy, Ltd.," Hitachi Hyoron, vol. 90, no. 1, p. 13, Jan. 2008.

(6) Masaharu HANYU. "Challenges to Achieve Globalization in Nuclear Business," Hitachi Hyoron, vol. 90, no. 2, pp. 13-15, Feb. 2008.

(7) Masahito YOSHIMURA et al. "Prospect of Hitachi Nuclear Business (Boiling Water Reactor)" Hitachi Review, vol. 58, no. 2, pp. 42-47, May 2009.

(8) Takashi IKEGUCHI et al. "Development of Electricity and Energy Technologies for Low-Carbon Society," Hitachi Review, vol. 59, no. 3, pp. 53-59, Aug. 2010.

(9) Terufumi KAWASAKI et al. "Development of CCS (Carbon Capture and Storage) Technology to Combat Climate Change," Hitachi Review, vol. 59, no. 3, pp. 83-88, Aug. 2010.

(10) Christian BERGINS et al. "Highly Efficient Power Stations with Carbon Capture," Hitachi Review, vol. 59, no. 3, pp. 89-93, Aug. 2010.

(11) Nobuo NAGASAKI et al. "Progress toward Commercializing New Technologies for Coal Use," Hitachi Review, vol.. 59, no. 3, pp. 77-82, Aug. 2010.

(12) Kenichi OCHI et al. "Latest Low-NOx Combustion Technology for Pulverized-coal-fired Boilers," Hitachi Review, vol. 58, no. 5, pp. 187-193, Oct. 2009.

(13) Osamu ITO et al. "CO 2 Reduction Technology for Thermal Power Plant Systems," Hitachi Review, vol. 57, no. 5, pp. 166-172, Sept. 2008.

(14) Hirofumi KIKKAWA et al. "DeNOx, DeSOx, and $\mathrm{CO}_{2}$ Removal Technology for Power Plant,” Hitachi Review, vol. 57, no. 5, pp. 174-178, Sept. 2008.

(15) Hidefumi ARAKI et al. "Ambient Temperature and Part-load Characteristics of the Advanced Humid Air Turbine System," Proceedings of JSME Power \& Energy System Division Symposium, June 2010.

(16) Hisafumi OJIMA et al. "Efforts of Environmental Management in the Hitachi Group," 
Hitachi Review, vol. 57. no. 5, pp. 160-165, Sept. 2008.

(17) Hidetoshi FUJII et al. "A High-efficiency Steam Turbine Utilizing Optimized Reaction Blades," Hitachi Review, vol. 56, no. 4, pp. 104-108, Nov. 2007.

(18) Kazuhiro IMAIE et al. "Power Stabilization Technologies for Next-generation Transmission and Distribution Networks," Hitachi Review, vol. 59, no. 3, pp. 106-110, Aug. 2010.

(19) Wina GRAUS. "International Comparison of Fossil Power Efficiency and $\mathrm{CO}_{2}$ Intensity," (commissioned by the Federation of Electric Power Companies of Japan), Ecofys, November 2009. 